\title{
Fatores de virulência em linhagens de Escherichia coli isoladas de mastite bovina
}

[Virulence factors in Escherichia coli strains isolated from bovine mastitis]

\author{
M.G. Ribeiro ${ }^{1}$, E.O. Costa $^{2}$, D.S. Leite ${ }^{3}$, H. Langoni ${ }^{1}$, F. Garino Júnior ${ }^{2}$, C. Victória ${ }^{1}$, F.J.P. Listoni ${ }^{1}$ \\ ${ }^{1}$ Faculdade de Medicina Veterinária e Zootecnia - UNESP \\ Caixa Postal 560 \\ 18.618-000 - Botucatu, SP \\ ${ }^{2}$ NAPGAMA-FMVZ-USP- São Paulo, SP \\ ${ }^{3}$ UNICAMP- Campinas, SP
}

\begin{abstract}
RESUMO
Avaliou-se a ocorrência de fatores de virulência e do sorotipo O157:H7 em 120 linhagens de Escherichia coli, isoladas de 80 casos de mastite clínica bovina e 40 de mastite subclínica. Verificou-se alfahemolisina em oito $(6,7 \%)$ linhagens, isoladas de cinco casos de mastite clínica e três de mastite subclínica e em nenhuma das estirpes detectou-se enteroemolisina. A presença de sideróforos foi encontrada em $11(9,2 \%)$ linhagens, sete de mastite clínica e quatro de subclínica. Em duas $(1,7 \%)$ estirpes isoladas de mastite subclínica, identificou-se enterotoxina STa. Observou-se efeito citopático em células vero compatível com a produção de verotoxina-VT em cinco $(4,2 \%)$ linhagens, duas de mastite clínica e três subclínicas. Em uma $(0,8 \%)$ linhagem isolada de mastite clínica, detectou-se efeito citopático compatível com o fator necrosante citotóxico. Nenhuma estirpe apresentou-se sorbitol-negativa no MacConkey-sorbitol, tampouco aglutinou com o sorotipo O157:H7. Os antimicrobianos mais efetivos foram polimixina B $(97,5 \%)$ e norfloxacina $(95,8 \%)$. Observou-se multi-resistência a dois ou mais antimicrobianos em 24 (20\%) estirpes, principalmente com o uso de ampicilina e ceftiofur.
\end{abstract}

Palavras-chave: bovino, mastite, Escherichia coli, virulência, toxina, sorotipo O157:H7

\begin{abstract}
The occurrence of different virulence factors and O157:H7 serotype investigation in 120 Escherichia coli strains isolated from clinical (80 cases) and subclinical (40 cases) bovine mastitis was evaluated. Alphahaemolysin was detected in $8(6.7 \%)$ strains (5 clinical and 3 subclinical cases). None strain showed enterohaemolysin production. E. coli growth under iron restriction conditions (siderophores production) was observed in $11(9.2 \%)$ strains (7 clinical and 4 subclinical cases). STa enterotoxin was detected in 2 (1.7\%) strains from subclinical cases. Cytotoxic effect in vero cells compatible with verotoxin-VT production was observed in $5(4.2 \%)$ strains (2 clinical and 3 subclinical cases). One strain (0.8\%) isolated from clinical mastitis showed cytophatic effect in vero cells compatible with cytotoxic-necroticfactor production. None strain showed non-sorbitol fermenting colonies using sorbitol MacConkey agar and agglutination with specific anti-sera for E. coli O157:H7 serotype investigation. Polymixin B (97.5\%) and norfloxacin (95.8\%) were the most effective drugs. Multiple-drug resistance for 2 or more antimicrobials was observed in $24(20.0 \%)$ strains, mainly with use of ampicillin and ceftiofur.
\end{abstract}

Keywords: bovine, mastitis, Escherichia coli, virulence, toxin, serotype O157:H7

Recebido em 21 de outubro de 2004

Aceito em 19 de dezembro de 2005

E-mail: mgribeiro@fmvz.unesp.br

Apoio: $\mathrm{CNPq}$ 


\section{INTRODUÇÃO}

Escherichia coli é um dos mais prevalentes microrganismos de origem ambiental, na gênese da mastite bovina. As infecções mamárias por $E$. coli ocorrem sob a forma clínica, de maneira hiperaguda ou aguda, nas primeiras semanas pósparto, caracterizadas pela difícil resolução terapêutica, nos casos com comprometimento sistêmico, e morte ocasional de animais por toxemia (Jones, 1990; Radostits et al., 2000). O microrganismo também tem sido investigado em casos de mastite subclínica bovina (Döpfer et al., 1999; Ribeiro, 2001).

A pluralidade dos fatores de virulência de $E$. coli desperta a preocupação com o envolvimento destes mecanismos de virulência em estirpes isoladas de mastite bovina. Estes fatores são constituídos por componentes lipopolissacarídicos-LPS da estrutura bacteriana (endotoxinas), ou são representados por diferentes cito ou exotoxinas (hemolisinas, fator necrosante citotóxico-CNF, verotoxinas-VT, enterotoxinas), assim como propriedades que permitem a multiplicação em meios com restrição de ferro (sideróforos), a multirresistência aos antimicrobianos, ou a colonização celular (pili, adesinas ou fímbrias) (Sussman, 1997).

As diferentes linhagens de E. coli responsáveis principalmente por distúrbios entéricos são agrupadas em seis tipos: enterotoxigênicas, enteroinvasoras, enteropatogênicas, enterohemorrágicas, enteroagregativas e de aderência difusa, subdivididas, fundamentalmente, pela capacidade de produção de determinadas toxinas, de invasão celular ou de manifestação de sintomas clínicos no homem e/ou nos animais (Gyles, 1992; Ribeiro et al., 1999). Recentemente, E. coli enteroemorrágica sorotipo O157:H7 tem emergido como causa de graves manifestações clínicas de colite hemorrágica, trombocitopenia e distúrbios renais no homem, freqüentemente fatais em crianças.

Estudos epidemiológicos relacionam os casos de doença humana pelo sorotipo O157:H7, com o consumo de carne de origem bovina, principalmente hambúrgueres, leite e derivados, submetidos ou não à pasteurização, verduras, frutas e água. Alguns pacientes podem evoluir para grave acometimento renal denominado síndrome urêmica hemolítica, provocado por lesões no endotélio vascular renal, atribuídas à ação de verotoxinas absorvidas a partir do epitélio intestinal (Sussman, 1997; Tauxe, 1997). No Brasil são escassos os estudos conduzidos na investigação de fatores de virulência em estirpes de E. coli isoladas de mastite bovina. O presente estudo objetivou determinar a ocorrência de alfahemolisinas, enteroemolisinas, sideróforos, enterotoxina STa, CNF, VT, multirresistência aos antimicrobianos e do sorotipo O157:H7 em linhagens de E. coli isoladas do leite de bovinos com mastite.

\section{MATERIAL E MÉTODOS}

Foram utilizadas 120 linhagens de E. coli isoladas de 80 casos de mastite clínica e 40 de mastite subclínica em bovinos, entre o período de janeiro de 1998 a dezembro de 2003. O diagnóstico de mastite clínica foi realizado com auxílio da prova da caneca telada de fundo escuro, e na presença de sinais de inflamação na glândula mamária e/ou sistêmicos nos animais (Radostits et al., 2000). A mastite subclínica foi caracterizada utilizando o California Mastitis Test (CMT) (escores 1+ a 3+) (Schalm et al., 1971). Foram incluídas no estudo somente estirpes de E. coli com isolamento puro, com 20 ou mais colônias. As amostras de leite foram semeadas em ágar sangue ovino desfibrinado $(5 \%)$ e ágar MacConkey, mantidas a $37^{\circ} \mathrm{C}$, em aerobiose, por 48 horas. As linhagens de E. coli foram identificadas segundo suas características morfotintoriais, bioquímicas e de cultivo (Krieg e Holt, 1994).

A detecção de hemolisina, enteroemolisina, sideróforos, enterotoxina STa, CNF, VT, sensibilidade microbiana e do sorotipo O157:H7 foi realizada nas 120 linhagens de E. coli.

Alfa-hemolisina foi diagnosticada em ágar sangue ovino desfibrinado $(5 \%)$, a $37^{\circ} \mathrm{C}$, em aerobiose, avaliada com quatro e 24 horas; as linhagens com halo de hemólise total foram consideradas alfa-hemolíticas (Sussman, 1997). Como controle utilizou-se cepa de E. coli hemolítica P46. Enteroemolisina foi identificada pelo cultivo do agente em ágar tríptico de sojaTSA, acrescido de $10 \mathrm{mM}$ de $\mathrm{CaCl}_{2}$ e sangue ovino desfibrinado (5\%), não lavado e lavado por centrifugações em PBS. As placas foram 
observadas após quatro e 24 horas de incubação, em aerobiose, a $37^{\circ} \mathrm{C}$. Repetiu-se o mesmo procedimento utilizando sangue bovino (5\%). Halo de hemólise parcial, no meio com hemácias lavadas, foi considerado enteroemolisinapositivo (Catani, 1999). Como controle foi utilizada $E$. coli $\mathrm{C} 3888$.

Colônias isoladas de $E$. coli foram cultivadas em ágar nutriente contendo $200 \mu \mathrm{M}$ de Dipiridila, a $37^{\circ} \mathrm{C}$, em aerobiose, por $24 \mathrm{~h}$ (Ferreira e Bottino, 1998). Esse procedimento foi repetido três vezes, consecutivamente, em intervalos de $24 \mathrm{~h}$. Ao final da terceira passagem, as estirpes de E. coli com multiplicação no meio contendo Dipiridila foram consideradas sideróforo-positivas. Como controle positivo, foi utilizada cepa de E. coli K12.

Procedeu-se à detecção de enterotoxina STa utilizando o ensaio biológico em camundongos (Dean et al., 1972), inoculando sobrenadante das culturas adicionado de azul de Evans (2\%) em camundongos tipo Swiss. Após a eutanásia, as estirpes que mostraram valores iguais ou superiores a 0,07 (relação peso do intestino e peso da carcaça) foram consideradas positivas. Como controle positivo, foi utilizada $E$. coli O101:H-, K99, STa +.

Colônias isoladas foram submetidas à extração de citotoxinas para detecção de CNF e VT utilizando caldo tríptico de soja-TSB, acrescido de mitomicina C. O sobrenadante foi inoculado em células vero, com efeito citopático avaliado com 24, 48 e 72 horas (Della Colleta, 1997). Consideram-se como CNF-positivas as linhagens que induziram à formação de células gigantes, multinucleadas e à perda da viabilidade celular (destruição da monocamada), enquanto o efeito inicial de alongamento, seguido da perda da viabilidade celular, foi considerado positivo para VT (Gyles, 1992; Sussman, 1997). Como controle positivo, foram utilizadas $E$. coli MR48 (CNF1), B26a (CNF2), H30 (VT1) e J2 (VT2).

Procedeu-se ao teste de sensibilidade microbiana - método de difusão com discos - (Bauer et al., 1966), utilizando-se os seguintes antimicrobianos: amicacina $(30 \mathrm{mcg})$, ampicilina $(10 \mathrm{mcg})$, cefoperazona sódica $(75 \mathrm{mcg})$, ceftiofur (30 mcg), ciprofloxacina $(5 \mathrm{mcg})$, enrofloxacina (5mcg), florfenicol (30mcg), gentamicina $(10 \mathrm{mcg})$, neomicina $(30 \mathrm{mcg})$, norfloxacina (10mcg), polimixina B (300 unidades) e sulfadiazina/trimetoprim $(25 \mathrm{mcg})$.

As linhagens foram semeadas no ágar MacConkey-sorbitol, mantidas à temperatura de $37^{\circ} \mathrm{C}$, em aerobiose, por 48 horas, para identificação de estirpes não fermentadoras de sorbitol. A presença de colônias incolores foi considerada sorbitol-negativa (Vernozy-Rozand, 1997). Independentemente da fermentação no ágar MacConkey-sorbitol, todas as linhagens foram submetidas ao teste de aglutinação em lâmina, em triplicata, utilizando anti-soros para $\mathrm{O} 157^{1}$ e $\mathrm{H}^{2}$. Como controle de E. coli $\mathrm{O} 157: \mathrm{H} 7$, foi utilizada cepa EDL 933.

A associação entre a presença de mastite clínica ou subclínica e a ocorrência dos diferentes fatores de virulência foram avaliadas pelo método de qui-quadrado (exato de Fisher), utilizando o programa Epi-Info (versão 6.04) (Dean et al., 1994), considerando diferença significativa para valores de $\mathrm{P}<0,01$.

\section{RESULTADOS}

$\mathrm{Na}$ Tab.1 apresentam-se os fatores de virulência detectados em 120 linhagens de E. coli isoladas de mastite bovina.

Verificou-se alfa-hemolisina em oito (6,7\%) linhagens de $E$. coli, isoladas de cinco (4,2\%) casos de mastite clínica e três $(2,5 \%)$ de mastite subclínica. Não se detectou nenhuma estirpe produtora de enteroemolisina. Linhagens sideróforo-positivas foram observadas em 11 $(9,2 \%)$ animais, das quais sete $(5,8 \%)$ provenientes de casos de mastite clínica e quatro $(3,3 \%)$ subclínicas. Em duas $(1,7 \%)$ estirpes isoladas de mastite subclínica foram detectadas a produção de enterotoxina STa. O efeito citopático em células vero compatível com a produção de VT foi encontrado em cinco (4,2\%) linhagens, duas $(1,7 \%)$ isoladas de mastite clínica e três $(2,5 \%)$ subclínicas. Em um $(0,8 \%)$ isolado, diagnosticado em animal com mastite clínica, verificou-se efeito citopático compatível com CNF.

\footnotetext{
${ }^{1}$ Probac do Brasil - Produtos Bacteriológicos Ltda - São

Paulo, SP ${ }^{\circledR}$

${ }^{2}$ Difco - Laboratórios Difco Ltda ${ }^{\circledR}$
} 
Tabela 1. Ocorrência de diferentes fatores de virulência em 120 linhagens de Escherichia coli isoladas de mastite bovina

\begin{tabular}{|c|c|c|c|c|c|c|}
\hline Animal & Mastite & $\begin{array}{c}\text { Alfa- } \\
\text { hemolisina }\end{array}$ & Sideróforo & $\begin{array}{c}\text { Enterotoxina } \\
\text { STa }\end{array}$ & $\begin{array}{l}\text { Efeito citopático em } \\
\text { células vero }\end{array}$ & $\begin{array}{l}\text { Multi-resistência a dois ou } \\
\text { mais antimicrobianos }\end{array}$ \\
\hline 4 & subclínica & -- & -- & positivo & -- & -- \\
\hline 7 & subclínica & -- & positivo & -- & -- & 3 drogas \\
\hline 9 & subclínica & -- & positivo & -- & -- & -- \\
\hline 17 & clínica & -- & positivo & -- & -- & -- \\
\hline 25 & clínica & -- & positivo & -- & -- & 2 drogas \\
\hline 26 & clínica & -- & positivo & -- & -- & 3 drogas \\
\hline 42 & subclínica & positivo & -- & positivo & $\begin{array}{l}\text { alongamento e morte } \\
\text { celular (VT) }\end{array}$ & -- \\
\hline 46 & clínica & -- & positivo & -- & -- & -- \\
\hline 47 & clínica & positivo & -- & -- & $\begin{array}{l}\text { células gigantes, multi- } \\
\text { nucleadas (CNF) }\end{array}$ & -- \\
\hline 51 & clínica & positivo & -- & -- & -- & -- \\
\hline 77 & clínica & -- & positivo & -- & -- & -- \\
\hline 78 & subclínica & positivo & -- & -- & $\begin{array}{l}\text { alongamento e morte } \\
\text { celular (VT) }\end{array}$ & 3 drogas \\
\hline 79 & clínica & -- & positivo & -- & -- & -- \\
\hline 81 & subclínica & positivo & -- & -- & -- & -- \\
\hline 82 & clínica & positivo & -- & -- & -- & 4 drogas \\
\hline 83 & clínica & -- & positivo & -- & -- & 2 drogas \\
\hline 84 & clínica & positivo & -- & -- & -- & -- \\
\hline 89 & clínica & -- & -- & -- & $\begin{array}{l}\text { alongamento e morte } \\
\text { celular (VT) }\end{array}$ & -- \\
\hline 92 & clínica & positivo & -- & -- & -- & -- \\
\hline 95 & clínica & -- & -- & -- & $\begin{array}{l}\text { alongamento e morte } \\
\text { celular (VT) }\end{array}$ & 3 drogas \\
\hline 97 & subclínica & -- & positivo & -- & -- & -- \\
\hline 112 & subclínica & -- & positivo & -- & -- & 2 drogas \\
\hline 120 & subclínica & -- & -- & -- & $\begin{array}{l}\text { alongamento e morte } \\
\text { celular (VT) }\end{array}$ & -- \\
\hline
\end{tabular}

$\mathrm{VT}=$ verotoxina; $\mathrm{CNF}=$ fator necrosante citotóxico.

Não se observou nenhuma estirpe de E. coli sorbitol-negativa no ágar MacConkey-sorbitol, tampouco aglutinação com o sorotipo O157:H7. Na Tab. 2, são apresentados os resultados do teste de sensibilidade microbiana in vitro das linhagens de E. coli frente a 12 antimicrobianos. Os maiores índices de sensibilidade do agente foram verificados para polimixina B, norfloxacina e ciprofloxacina. Os maiores índices de resistência foram observados com o uso da ampicilina e do ceftiofur. Constataram-se linhagens de E. coli resistentes a dois ou mais antimicrobianos em $24(20 \%)$ estirpes. Não foi encontrada associação significativa $(\mathrm{P}>0,01)$ entre a presença de mastite clínica ou subclínica e a ocorrência dos fatores de virulência.

\section{DISCUSSÃO E CONCLUSÕES}

Classicamente os casos de mastite por E. coli são descritos como manifestações clínicas hiperagudas ou agudas, nas primeiras semanas de lactação, com morte ocasional de animais (Jones, 1990). Nos últimos anos, observa-se em outros países a preocupação com os casos subclínicos de mastite bovina por E. coli. Sugere-se que a mastite subclínica por E. coli está associada a rebanhos com bom controle de mastite do tipo contagiosa, resultando em infecções persistentes na glândula mamária, tanto na lactação quanto no período seco (Döpfer et al., 1999; Radostitis et al., 2000). Ribeiro (2001), no Brasil, também ressaltou o envolvimento de estirpes de $E$. coli em bovinos com mastite subclínica ao analisar 11.125 amostras de leite de propriedades rurais dos estados de São Paulo e Minas Gerais. 
Tabela 2. Sensibilidade microbiana na prova de difusão com discos em 120 linhagens de Escherichia coli isoladas de mastite bovina

\begin{tabular}{lccc}
\hline \multirow{2}{*}{ Antimicrobiano } & \multicolumn{3}{c}{ Número de linhagens (\%) } \\
\cline { 2 - 4 } & Sensível & Parcialmente sensível & Resistente \\
\hline Amicacina (30mcg) & $62(51,7)$ & $49(40,8)$ & $9(7,5)$ \\
Ampicilina (10mcg) & $50(41,7)$ & $41(34,2)$ & $29(24,1)$ \\
Cefoperazona (75mcg) & $92(76,6)$ & $26(21,7)$ & $2(1,7)$ \\
Ceftiofur (30mcg) & $27(22,5)$ & $77(64,2)$ & $16(13,3)$ \\
Ciprofloxacina (5mcg) & $95(79,2)$ & $25(20,8)$ & $0(--)$ \\
Enrofloxacina (5mcg) & $91(75,8)$ & $23(19,2)$ & $6(5,0)$ \\
Florfenicol (30mcg) & $56(46,7)$ & $60(50,0)$ & $4(3,3)$ \\
Gentamicina (10mcg) & $83(69,2)$ & $27(22,5)$ & $10(8,3)$ \\
Neomicina (30mcg) & $26(21,7)$ & $84(70,0)$ & $10(8,3)$ \\
Norfloxacina (10mcg) & $115(95,8)$ & $5(4,2)$ & $0(--)$ \\
Polimixina B (300 unidades) & $117(97,5)$ & $3(2,5)$ & $0(--)$ \\
Sulfa / trimetoprim (25mcg) & $91(75,8)$ & $14(11,7)$ & $15(12,5)$ \\
\hline Sulfa = sulfametoxazole & & &
\end{tabular}

Sulfa $=$ sulfametoxazole.

Polimixina B, norfloxacina e ciprofloxacina apresentaram alta efetividade in vitro nas 120 linhagens de E. coli, embora esses princípios ativos não estejam disponíveis comercialmente no país para infusão intramamária (Andrade et al., 2001), o que limita a indicação dessas drogas na terapia da mastite bovina. A crescente descrição de resistência múltipla em estirpes de E. coli isoladas do leite de bovinos (Stephan e Kuhn, 1999) tem alertado para o risco de veiculação de linhagens multirresistentes para o homem, mediante o consumo de leite e/ou derivados. Neste estudo, $20 \%$ das linhagens de $E$. coli mostraram resistência a dois ou mais antimicrobianos, incluindo drogas consideradas efetivas na terapia do agente (Tab. 2). Presumese que ocorrência crescente de E. coli multirresistentes em casos de mastite bovina possa decorrer do uso indiscriminado de antimicrobianos na terapia intramamária e/ou parenteral, no emprego de subdosagens (Costa et al., 1997), ou mesmo no tratamento sem o respaldo de testes de sensibilidade microbiana, recaindo a escolha da droga na experiência de terapias anteriores ou no apelo comercial dos produtos.

Somente duas linhagens de E. coli foram produtoras de enterotoxina STa. Este resultado coincide com os assinalados por Sanches-Carlo et al. (1984) e Barrow e Hill (1989), que detectaram a enterotoxina $\mathrm{STa}$, respectivamente, em $0,5 \%$ e $1,0 \%$ de animais com mastite clínica. Lipman et al. (1995), em investigação similar, não evidenciaram a produção de STa em $E$. coli isoladas de mastite bovina. A ausência ou baixa produção de enterotoxina STa em $E$. coli isolada de mastite bovina revela, possivelmente, o reduzido envolvimento desse fator de virulência em infecções mamárias, a despeito do seu impacto em distúrbios entéricos.

O íon ferro é considerado elemento essencial no metabolismo bacteriano. Determinadas linhagens de E. coli possuem mecanismos de captação exógena do íon ferro, como a síntese de exoproteínas reconhecidas como sideróforos e hemolisinas. A capacidade de $E$. coli de competir e disponibilizar o ferro no organismo animal, ou mesmo adaptar-se à multiplicação em baixas concentrações do íon, é considerada importante mecanismo de virulência, principalmente em infecções extra-intestinais, incluindo na mastite (Sussman, 1997).

A presença de sideróforos foi observada em onze $(9,2 \%)$ das 120 linhagens de E. coli de bovinos com mastite, sete das quais isoladas de animais com mastite clínica e quatro subclínicas. Kaipainen et al. (2000) obtiveram resultados similares, encontrando sideróforos em $8 \%$ de 274 linhagens de E. coli isoladas de mastite clínica bovina.

Nas 120 linhagens de E. coli foram isoladas oito $(6,7 \%)$ produtoras de alfa-hemolisina. Tais resultados confirmam os de Barrow e Hill (1989), que evidenciaram 5\% de 237 E. coli alfahemolíticas em bovinos com mastite.

As enteroemolisinas são outro tipo de hemolisinas relacionadas recentemente às 
linhagens verotoxigênicas de $E$. coli, isoladas de pacientes humanos com distúrbios entéricos e renais, incluindo no Brasil (Guth et al., 2002). Em animais, as enteroemolisinas estão associadas às linhagens de $E$. coli isoladas de bovinos com e sem diarréia. Hogan et al. (1990) notificaram a produção de enteroemolisina em, respectivamente, $3,9 \%$ e $2,6 \%$ das estirpes submetidas ao meio contendo hemácias lavadas de ovinos e bovinos, em $76 \mathrm{E}$. coli isoladas de mastite clínica bovina. Nos 120 isolados de $E$. coli obtidos de mastite bovina, não foi possível determinar a presença de efeito lítico compatível com a produção de enteroemolisina. Dessa forma, presume-se que os mecanismos de captação de ferro exógeno - sideróforos, alfahemolisinas e enteroemolisinas - devem contribuir na virulência de $E$. coli no desenvolvimento da mastite, embora, provavelmente, não representem mecanismos essenciais na ocorrência de infecções clínicas ou subclínicas na glândula mamária bovina.

A descrição de CNF no homem é ligada a distúrbios entéricos, infecções do trato urinário e septicemias. À semelhança com o homem, nos animais o CNF também está estreitamente associado às infecções extra-intestinais, principalmente em estirpes de E. coli produtoras de alfa-hemolisinas (Sussman, 1997). Em células vero, o CNF induz a formação de células gigantes, multinucleadas, e morte celular (Gyles, 1992). Pohl et al. (1993), Lipman et al. (1995) e Kaipainen et al. (2000) notificaram a produção de linhagens de $E$. coli necrotoxigênicas, produtoras de hemolisinas, em bovinos com mastite clínica. A produção simultânea de CNF, de alfa-hemolisina e de sideróforos tem sido relatada em bovinos com mastite (Pohl et al., 1993; Kaipainen et al., 2000). No Brasil, Ribeiro et al. (2002) descreveram linhagem de E. coli produtora de CNF, alfa-hemolisina e sideróforo em vaca com mastite clínica hiper-aguda. De maneira similar, detectou-se a produção de $\mathrm{CNF}$ e alfa-hemolisina em um animal com mastite clínica, indicando que, provavelmente, as estirpes produtoras de CNF, hemolisinas e/ou sideróforos, deteriam mecanismos adicionais de virulência e estariam associadas, predominantemente, a casos clínicos de inflamação na glândula mamária em bovinos.

É crescente a preocupação com a investigação de $E$. coli verotoxigênicas isoladas do leite de bovinos (Lipman et al., 1995; Sussman, 1997). Stephan e Khun (1999) notificaram quatro $(2,8 \%)$ E. coli verotoxigênicas, dentre 145 estirpes isoladas de mastite bovina. Neste estudo, foram encontrados cinco isolados mostrando efeito citopático compatível com a produção de VT em dois animais com mastite clínica e em três com mastite subclínica. Linhagens de E. coli verotoxigênicas, da classe enteroemorrágica sorotipo $\mathrm{O} 157: \mathrm{H} 7$, são reconhecidas nos últimos anos como agentes emergentes de zoonoses, relacionadas ao consumo pelo homem de produtos e subprodutos de origem bovina, especialmente carne e leite (Ribeiro et al., 1999). Evidências epidemiológicas têm relacionado o consumo de leite in natura a casos severos de colite hemorrágica e síndrome urêmica hemolítica no homem, assim como a identificação do sorotipo $\mathrm{O} 157: \mathrm{H} 7$ no leite de bovinos, após surtos de doença no homem (Tauxe, 1997). No Brasil, considera-se que Cerqueira et al. (1999) descreveram pela primeira vez E. coli $\mathrm{O} 157: \mathrm{H} 7 \mathrm{em}$ amostras fecais de bovinos encaminhados para o abate.

Nenhuma das 120 linhagens de E. coli isoladas de mastite - produtoras ou não de verotoxinas -, caracterizou-se como não fermentadora do sorbitol ou apresentou aglutinação para o sorotipo O157:H7. Este resultado difere dos encontrados em outros países, que têm notificado E. coli O157:H7 no leite bovino. Essas divergências dificultam o esclarecimento se $E$. coli sorotipo $\mathrm{O} 157: \mathrm{H} 7$ poderia ser considerado agente primário de mastite, ou ocorreria contaminação cruzada do leite com fezes de animais durante a ordenha, ou no processamento do produto e seus derivados (Tauxe, 1997; Ribeiro et al., 1999). Desse modo, permanece incerta a participação de E. coli $\mathrm{O} 157: \mathrm{H} 7$ na gênese de casos de mastite bovina no Brasil, embora a severidade das infecções humanas por E. coli $\mathrm{O} 157: \mathrm{H} 7$ apontem para a necessidade de estudos no país, com o intuito de avaliar a participação desse sorotipo em estirpes de E. coli isoladas do leite e derivados de origem animal, visando à vigilância epidemiológica do agente. A presença de linhagens de $E$. coli citotoxigênicas e multirresistentes aos antimicrobianos isoladas do leite de fêmeas bovinas, aliado ao hábito de consumo do produto in natura no país e/ou o uso na produção de derivados sem tratamento térmico adequado, alerta para o risco em saúde pública representado pela veiculação para $o$ 
homem - pelo leite - de E. coli com reconhecido potencial de patogenicidade.

\section{AGRADECIMENTOS}

À Dra. Mariza Landgraf da Faculdade de Ciências Farmacêuticas da USP, São Paulo, SP, pela cepa EDL 933; ao Dr. Antônio José Piantino Ferreira da FMVZ-USP, São Paulo, SP, pela cepa de E. coli K12; ao Dr. Domingos da Silva Leite da Unicamp, Campinas, SP, pela cepa O101:H-,K99 ${ }^{+} \quad\left(\mathrm{STa}^{+}\right)$, assim como pela disponibilização das cepas controle-positivas C3888 (enterohemolisina) (Dr. Lothar Beutin do Instituto Robert Koch, Alemanha); MR48 (CNF1) e B26a (CNF2) (Jorge Blanco da Universidade de Santiago de Compostela, Espanha); H30 (VT1) e J2 (VT2) (Dr. J. Konowalchuck e Dr. Y. Yakeda do International Medical Center, Japão), cedidas da bacterioteca do Laboratório de Antígenos Bacterianos do Departamento de Microbiologia e Imunologia da Unicamp.

\section{REFERÊNCIAS BIBLIOGRÁFICAS}

ANDRADE, S.F.; GIUFFRIDA, R.; RIBEIRO, M.G. Quimioterápicos antimicrobianos e Antibióticos. In: ANDRADE, S.F. Manual de terapêutica veterinária. 2.ed. Roca: São Paulo, 2001. p.13.58

BARROW, P.A.; HILL, A.W. The virulence characteristics of strains of Escherichia coli isolated from cases of bovine mastitis in England and Wales. Vet. Microbiol., v. 20, p. 35-48, 1989.

BAUER, A.W.; KIRBY, W.M.M.; SHERRIS, J.C. et al. Antibiotic susceptibility testing by a standardized single disk method. Am. J. Clin. Pathol., v.45, p.493-496, 1966.

CATANI, C.F. Purificação e caracterização de enterohemolisina produzida por Escherichia coli enteropatogêncicas. 1999. 101f. Tese (Doutorado) - Instituto de Biologia, Universidade Estadual de Campinas, Campinas, SP

CERQUEIRA, A.M.F.; GUTH, B.E.C.; JOAQUIM, R.M. et al. High occurrence of Shiga toxin-producing Escherichia coli (STEC) in healthy cattle in Rio de Janeiro State, Brazil. Vet. Microbiol., v.70, p.111-121, 1999.

COSTA, E.O. Uso de antimicrobianos na mastite. In: SPINOSA, H.S.; GÓRNIAK, S.L.; BERNARDI, M.M. Farmacologia aplicada à medicina veterinária. Rio de Janeiro: Guanabara Koogan, 1997. p.387-397.

DEAN, A.G.; CHING, Y.C.; WILLIAMS, R.G. et al. Test for Escherichia coli enterotoxin using infant mice: application in a study of diarrhea in children in Honolulu. J. Infect. Dis., v.125, p.407-411, 1972.

DEAN, A.G.; DEAN, J.A.; COULOMBIER, D. et al. Epi Info Version 6. A Word Processing, Database and Statistical Program for Epidemiology on Microcomputers. Atlanta: Centers for Disease Control and Prevention, 1994. 601p.

DELLA COLLETA, H.H.M.D. Purificação $e$ caracterização do fator necrosante citotóxico do tipo 2 (CNF 2) produzido por Escherichia coli. 1997. 103f. Dissertação (Mestrado). Instituto de Biologia, Universidade Estadual de Campinas, Campinas, SP.

DÖPFER, D.; BARKEMA, H.W.; LAM, T.J.G.M. et al. Recurrent clinical mastitis caused by Escherichia coli in dairy cows. J. Dairy Sci., v.82, p.80-85, 1999.

FERREIRA, A.J.P.; BOTTINO, J.A. Patogenia da colibacilose aviária. São Paulo: Departamento de Patologia da Faculdade de Medicina Veterinária e Zootecnia da USP, 1998. $31 \mathrm{p}$.

GUTH, B.E.C.; SOUZA, R.L.; VAZ, T.M.I. et al. First Shiga toxin-producing Escherichia coli isolate from a patient with hemolitic uremic syndrome, Brazil. Emerg. Infect. Dis., v.8, p.535536, 2002.

GYLES, C.L. Escherichia coli cytotoxins and enterotoxins. Can. J. Microbiol., v.38, p.734746, 1992.

HOGAN, J.S.; TODHUNTER, D.A.; SMITH, K.L. et al. Hemagglutination and hemolysis by Escherichia coli isolated from bovine intramammary infections. J. Dairy Sci., v.73, p.3126-3131, 1990.

JONES, T.O. Escherichia coli mastitis in dairy cattle. A review of the literature. Vet. Bull., v.60, p.205-231, 1990. 
KAIPAINEN, T.; POHJANVIRTA, T.; SHPIGEL, N.Y. et al. Virulence factors of Escherichia coli isolated from bovine clinical mastitis. In: INTERNATIONAL SYMPOSIUM ON IMMUNOLOGY OF RUMINANT MAMMARY GLAND, 1., 2000, Stressa. Proceedings... Stressa: Internacional Dairy Federation, 2000. p.314-318.

KRIEG, N.R.; HOLT, J.C. Bergey 's manual of sistematic bacteriology. 9.ed. Baltimore: Williams \& Wilkins, 1994. 984p.

LIPMAN, L.J.A.; NIJS, A.; GAASTRA, W. Isolation and identification of fimbriae and toxin production by Escherichia coli strains from cows with clinical mastitis. Vet. Microbiol., v.47, p.17, 1995.

POHL, P.; OSWALD, E.; MUYLEM, K. V. et al. Escherichia coli producing CNF1 and CNF2 cytotoxins in animals with different disorders. Vet. Res., v. 24, p. 311-315, 1993.

RADOSTITIS, O.M.; GAY, C.C.; BLOOD, D.C. et al. Veterinary medicine: a textbook of the diseases of cattle, sheep, pigs, goats and horses. 9.ed. London: W.B. Saunders, 2000b. p.603-700.

RIBEIRO, A.R. Estudo da mastite bovina causada por microrganismos ambientais: influência do manejo e higiene, sazonalidade e qualidade microbiológica da água. 2001. 138f. Tese (Doutorado) - Instituto de Biociências Universidade de São Paulo, São Paulo.

RIBEIRO, M.G.; COSTA, E.O.; LEITE, D.S. et al. Fator necrosante citotóxico em Escherichia coli isolada de mastite clínica bovina. Arq. Bras. Med. Vet. Zootec., v.54, p.648-650, 2002.

RIBEIRO, M.G.; SILVA, E.O.T.R.; PINTO, J.P.A.N. Escherichia coli O157:H7. De hambúerguer, leite e outros gêneros alimentícios à colite hemorrágica e síndrome urêmica hemolítica. Rev. Hig. Aliment., v.13, p.88-99, 1999.

SANCHES-CARLO, V.; McDONALD, J.S.; PACKER, R.A. Virulence factors of Escherichia coli isolated from cows with acute mastitis. Am. J. Vet. Res., v.45, p.1775-1777, 1984a.

SCHALM, O.W.; CARROL, E.; JAIN, N.C. Bovine mastitis. Philadelphia: Lea \& Febiger, 1971. 360p.

STEPHAN, R.; KUHN, K. Prevalence of verotoxigenic-producing Escherichia coli (VTEC) in bovine coli mastitis and their antibiotic resistance patterns. Zentralbl. Vet., v.46, p.423-427, 1999.

SUSSMAN, M. Escherichia coli: mechanisms of virulence. United Kingdom: Cambridge University, 1997. 639p.

TAUXE, R.V. Emerging foodborne diseases: an evolving public health challenge. Emerg. Infect. Dis., v.3, p.1-13, 1997.

VERNOZY-ROZAND, C. Detection of Escherichia coli O157:H7 and other verocytotoxin-producing $E$. coli (VTEC) in food. J. Appl. Microbiol., v.82, p.537-551, 1997. 